\title{
Thermal Medicine: Therapeutic and Preventive Evidence on Fibromyalgia
}

\author{
Tzouvara Sofia ${ }^{1 *}$, Kouskoukis Konstantinos ${ }^{2}$, Philippou Anastassios ${ }^{1}$, Mavragani Clio ${ }^{1}$ and \\ Koutsilieris Michael $^{1}$
}

${ }^{1}$ Department of Physiology, Medical School, National and Kapodistrian University of Athens, Greece

${ }^{2}$ Department of Medicine, Democritus University of Thrace, Greece

*Corresponding author: Tzouvara Sofia, Department of Physiology, Medical School, National and Kapodistrian University of Athens, Greece.

To Cite This Article: Tzouvara Sofia, Kouskoukis Konstantinos, Philippou Anastassios, Mavragani Clio, Koutsilieris Michael. Thermal Medicine: Therapeutic and Preventive Evidence on Fibromyalgia. Am J Biomed Sci \& Res. 2021 - 12(4). AJBSR.MS.ID.001769. DOI: 10.34297/ AJBSR.2021.12.001769.

Received: 眥 March 26, 2021; Published: 紫 April 16, 2021

\section{Mini Review}

A systematic literature search was conducted through March 2021 (Medline via Pubmed), using the keywords balneotherapy, mudtherapy, fibromyalgia, in order to assess the effectiveness of different forms of Thermal Medicine (TM) in the management of fibromyalgia syndrome (FMS). There were 20 Randomized Controlled Trials (RCTs) and 13 Systematic Reviews. The last Systematic Review was in April 2013, so we reviewed the 6 RCT's since Aril 2013.

FMS is an idiopathic, common and complex syndrome, defined as long lasting, widespread and symmetrical non-articular musculoskeletal pain with generalized tender points at specific anatomical sites [1]. FMS main symptom is pain, however, it can, also be combined with other functional symptoms, such as fatigue and sleep disturbances. [2]. Unfortunately, there is no clear evidence on FMS's etiology, and as a result, different therapeutic methods are based on several possible pathogenic mechanisms [3]. propose that FMS's inflammatory process can be mediated by cytokines, proteases and inflammation mediators, while Clauw et al. (2011) and Kaltsas G, et al. [4] suggest that FMS is caused by pathophysiological changes on hypothalamo-pituitary-adrenal axis, autonomic nervous system, cytokines, hormones and neurotransmitters, which lead to lower biological amines' levels and increase of the excretion of substance P.

TM is a complimentary therapeutic method that consists of Balneothetapy (BT), internal washes, drinking therapy, inhalation therapy, mud therapy (MT), thalassotherapy and cave therapy. The basic therapeutic elements, on which $\mathrm{TM}$ is based, are inorganic elements and nonmetals $\left(\mathrm{Cl}^{-}, \mathrm{SO}_{4}{ }^{2-}, \mathrm{HCO}_{3}^{-}, \mathrm{S}, \mathrm{Br}, \mathrm{I}, \mathrm{F}, \mathrm{NH}_{3}, \mathrm{NO}_{3}^{-}, \mathrm{NO}_{2}^{-}\right.$, $\left.\mathrm{PO}_{4}{ }^{3-}, \mathrm{H}_{2} \mathrm{PO}_{4}{ }_{4}, \mathrm{HPO}_{4}{ }^{2-}, \mathrm{CO}_{2}, \mathrm{O}_{2}, \mathrm{~N}_{2}, \mathrm{H}_{2}, \mathrm{Se}\right)$, microminerals $\left(\mathrm{Na}^{+}, \mathrm{K}^{+}, \mathrm{Ca}^{2+}\right.$, $\left.\mathrm{Mg}^{2+}, \mathrm{Fe}^{2+}, \mathrm{Fe}^{3+}, \mathrm{Cu}, \mathrm{Co}, \mathrm{Zn}, \mathrm{Ni}, \mathrm{Mn}, \mathrm{Li}^{+}, \mathrm{Al}, \mathrm{Ba}, \mathrm{Sr}^{2+}, \mathrm{Pb}, \mathrm{As}, \mathrm{B}\right)$ and noble gases (Rn, He, Ne, Ar, Kr) [5].

Hot thermal baths are thought to improve various FMS symptoms. Studies have shown that TM decreases pain moderately and improve the patients' Health-Related Quality of Life (HRQoL) [6-8], while it, also, has a small effect on mood [6]. TM might even be considered as a first-line treatment together with patient education and aerobic exercise [9]. The mechanism of action of this approach is still a matter of discussion, but probably involves hormonal, inflammatory and cognitive-emotional factors [10].

Different pathophysiological mechanisms are suggested to explain the therapeutic results of BT and MT on FMS patients. First of all, mechanical factor (buoyancy and aquatic resistance) relieves body from pain, due to the absence of gravity on joints and secondly, thermal factor (heat) affects nerve endings and provokes muscle relaxation [10]. Sukenik S et al. [11] described the antiinflammatory effects of sulphurous thermal water. Ardiç $\mathrm{F}$ et al. [12] proposed that BT therapeutic result on FMS is based on the decrease of IL-1, PGE2, and LTB4. Furthermore, Ardiç F et al. [10] \& Sukenik S et al. [13] suggest that increased plasma endorphin and cortisol levels, as well as the decrease of IL-1, IL-6, PGE2, LTB4, TNF-alpha are responsible of the therapeutic effect of BT on FMS.

Sulfur (S) is one of the main therapeutic elements of TM. It is structural element of proteins, hormones, enzymes, amino acids, 
muscles, skin, and bones, it promotes nervous system function and insulin production, and it provides anti-inflammatory, antitoxic, antiallergic, bactericidal and parasiticidal activity. Hydrogen sulfide (H2S) acts in inhalation and drinking therapy, as well as BT [14]. Sulphurous thermal water seems to reduce IL-2 and IFNY production (Ghersetich, 1996). Furthermore, Bellometti S et al. [15] has demonstrated that MT relieves pain and provokes muscle relaxation through an increase of $\beta$-endorphin plasma levels Bender $\mathrm{T}$ et al. [16]. Prior systematic reviews and meta-analyses concerning BT in FMS have covered the literature up to April 2013 [6] and found moderate evidence of a medium-to-large effect on pain and trigger-points-count (TBC) for BT, a medium effect on HRQoL, and no significant effect on depressive symptoms. Since 2015, Fioravanti A, Koçyiğit BF, Pérez-Fernández MR [7,17,18] published results about BT and its efficacy on FMS and [19-21] published results about BT and MT and their efficacy of FMS.

Koçyiğit BF et al. [17] compared the effect of a 21-sessions program (5days/week) on 66 patients, Fioravanti A et al. [7] evaluated the results of a 2-week program to those 3 and 6 months later (follow-up) and Pérez-Fernández MR et al. [18] compared the results of a 14-session/month program. All of them used Visual Analogue Scale (VAS), Tender Point Count (TPC), Fibromylagia Impact Questioning Total score (FIQ-Total), and Modified Fatigue Impact Scale (MFIS) for the evaluation of the patients. They concluded that BT eliminated pain, reduced the number of tender points and fatigue, both short- and long- term.

Bazzichi L et al. [19] compared the effect of a 2-week program (6 days/week) on 41 FM patients, Bağdatli AO et al. [20] studied the effect of a 2-week program (20min/day) on 70 patients and Ablin JN et al. [21] studied the effects of BT and MT on FMS in intermittent treatment program (2/week, 5 weeks) and continuous treatment program (5/weeks, 2 weeks). In all RCT, the results showed that symptoms have been alleviated, especially pain, while there was no difference between intermittent and continuous treatment. Studies show that TM alleviates symptoms on patients with FMS, specifically it eliminates pain, reduces the number of tender points, decreases fatigue, both short- and long-term. However, more RCTs are required in order to ensure the efficacy of TM on FMS [22-32].

\section{References}

1. Inanici F, Yunus MB (2004) History of Fibromyalgia: past to present Curr Pain Headache Rep 8(5): 369-378.

2. Sarzi-Puttini P, Giorgi V, Marotto D, Atzeni F (2020) Fibromyalgia: an update on clinical characteristics, aetiopathogenesis and treatment. Nature Reviews Rheumatology 16(11): 645-660.

3. Blanco LE, de Serres F, Fernandez-Bustillo E, Kassam DA, Arbesu D, et al. (2005) alpha1-Antitrypsin and Fibromyalgia: new data in favour of the inflammatory hypothesis of fibromyalgia. Med Hypotheses 64(4): 759-769.

4. Kaltsas G, Tsiveriotis K (2020) Fibromyalgia. In Endotext. MDText.com, Inc: South Dartmouth, MA, USA.
5. Kouskoukis K (2014) Health Tourism - Thermal Tourism - Thermalism. Kafkas. Athens, Greece.

6. Naumann J, Sadaghiani C (2014) Therapeutic benefit of balneotherapy and hydrotherapy in the management of fibromyalgia syndrome: a qualitative systematic review and meta-analysis of randomized controlled trials. Arthritis Res Ther 16(4): R141.

7. Fioravanti A, Patrizia Manica, Roberto Bortolotti, Gabriele Cevenini, Sara Tenti, et al. (2018) Is balneotherapy effective for fibromyalgia? Results from a 6-month double-blind randomized clinical trial. Clin Rheumatol 37(8): 2203-2212.

8. Honda Y, Junya Sakamoto, Yohei Hamaue, Hideki Kataoka, Yasutaka Kondo, et al. (2018) Effects of physical-agent pain relief modalities for fibromyalgia patients: a systematic review and meta-analysis of randomized controlled trials. Pain Res Manag.

9. Kurt EE, Koçak FA, Erdem HR, Tuncay F, Kelez F, et al. (2016) Which nonpharmacological treatment is more effective on clinical parameters in patients with fibromyalgia: balneotherapy or aerobic exercise? Arch Rheumatol 31(2): 162-169.

10. Guidelli GM, Tenti S, de Nobili E, Fioravanti A (2012) Fibromyalgia syndrome and spa therapy: myth or reality? Clin Med Insights Arthritis Musculoskelet Disord 5: 19-26.

11. Sukenik S, Flusser D, Abu-Shakra M (1999) The role of spa therapy in various rheumatic diseases. Rheum Dis Clin North Am 25(4): 883-897.

12. Ardiç F, Ozgen M, Aybek H, Rota S, Cubukçu D, et al. (2007) Effects of balneotherapy on serum IL-1, PGE2 and LTB4 levels in fibromyalgia patients. Rheumatol Int 27(5): 441-446.

13. Fraioli A, Grassi M, Mennuni G, Geraci A, Petraccia L, et al. (2013) Clinical research on the efficacy of spa therapy in fibromyalgia. A systematic review. Ann Ist Super Sanita 49(2): 219-229.

14. Kouskoukis K (2019) Thermal Medicine - Complementary methods. Doctors Media. Athens, Greece.

15. Bellometti S, Galzigna L (1999) Function of the hypothalamic adrenal axis in patients with fibromyalgia syndrome undergoing mud-pack treatment. Int J Clin Pharmacol Res 19(1): 27-33.

16. Bender T, Karagülle Z, Bálint GP, Gutenbrunner C, Bálint PV, et al. (2005) Hydrotherapy, balneotherapy, and spa treatment in pain management. Rheumatol Int 25(3): 220-224.

17. Koçyiğit BF, Gür A, Altındağ Ö, Akyol A, Gürsoy S, et al. (2016) Comparison of education and balneotherapy efficacy in patients with fibromyalgia syndrome: A randomized, controlled clinical study. Agri 28(2): 72-78.

18. Pérez-Fernández MR, Calvo-Ayuso N, Martínez-Reglero C, SalgadoBarreira Á, Muiño López-Álvarez JL, et al. (2019) Efficacy of baths with mineral-medicinal water in patients with fibromyalgia: a randomized clinical trial. Int J Biometeorol 63(9): 1161-1170.

19. Bazzichi L, Da Valle Y, Rossi A, Giacomelli C, Sernissi F, et al. (2013) A multidisciplinary approach to study the effects of balneotherapy and mud-bath therapy treatments on fibromyalgia. Clinical and experimental rheumatology 31(6 Suppl 79), S111-S120.

20. Bağdatli AO, Donmez A, Eröksüz R, Bahadır G, Turan M, et al. (2015) Does addition of 'mud-pack and hot pool treatment' to patient education make a difference in fibromyalgia patients? A randomized controlled single blind study. International journal of biometeorology 59(12): 1905-1911.

21. Eröksüz R, Erol Forestier FB, Karaaslan F, Forestier R, İşsever H, et al. (2020) Comparison of intermittent and consecutive balneological outpatient treatment (hydrotherapy and peloidotherapy) in fibromyalgia syndrome: a randomized, single-blind, pilot study. International journal of biometeorology 64(3): 513-520. 
22. Ablin JN, Hauser W, Buskila D (2013) Spa Treatment (Balneotherapy) for Fibromyalgia; A Qualitative-Narrative Review and a Historical Perspective. Evid Based Complement Alternat Med 638050.

23. Clauw DJ (2009) Fibromyalgia: an overview. Am J Med 122(12 suppl): S3-S13.

24. Clauw DJ, Arnold LM, Mc Carberg BH (2011) FibroCollaborative. The science of fibromyalgia. Mayo Clin Proc 86(9): 907-911.

25. Gutenbrunner C, Bender T, Cantista P, Karagülle Z (2010) A proposal for a worldwide definition of health resort medicine, balneology, medical hydrology and climatology. Int J Biometeorol 54(5): 495-507.

26. Langhorst J, Musial F, Klose P, Hauser W (2009) Efficacy of hydrotherapy in fibromyalgia syndrome - a meta-analysis of randomized controlled clinical trials. Rheumatology(oxford) 48(9): 1155-1159.

27. Neumann L, Sukenik S, Bolotin A, Abu-Shakra M, Amir M, et al. (2001) The effect of balneotherapy at the Dead Sea on the quality of life of patients with fibromyalgia syndrome. Clin Rheumatol 20(1): 15-19.
28. Nüesch E, Hauser W, Bernardy K, Barth J, Jüni P, et al. (2013) Comparative efficacy of pharmacological and non-pharmacological interventions in fibromyalgia syndrome: network meta-analysis. Ann Rheum Dis 72(6): 955-962.

29. Spaeth M (2009) Epidemiology, costs, and the economic burden of fibromyalgia. Arthritis Res Ther 11(3): 117.

30. Terhorst L, Schneider MJ, Kim KH, Goozdich LM, Stilley CS, et al. (2011) Complementary and alternative medicine in the treatment of pain in fibromyalgia: a systematic review of randomized controlled trials. J Manipulative Physiol Ther 34(7): 483-496.

31. Úbeda-D’Ocasar E, Jiménez Díaz-Benito V, Gallego-Sendarrubias GM, Valera-Calero JA, Vicario-Merino Á, et al. (2020) Pain and Cortisol in Patients with Fibromyalgia: Systematic Review and Meta-Analysis. Diagnostics (Basel) 10(11): 922. 